\title{
SOME LYAPUNOV-TYPE INEQUALITIES FOR A CLASS OF NONLINEAR SYSTEMS
}

\author{
XiaOJing Yang, Yong-In Kim And Kueiming Lo
}

Abstract. In this paper, we present some new Lyapunov-type inequalities for a class of nonlinear differential systems, which are natural generalizations of the well-known Lyapunov inequality for linear second order differential equations. The results of this paper generalize some previous results on this topic.

Mathematics subject classification (2010): 34C11.

Keywords and phrases: Lyapunov-type inequality, nonlinear differential system.

\section{REFERENCES}

[1] S. S. Cheng, Lyapunov inequalities for differential and difference equations, Fasc. Math. 23 (1991), $25-41$.

[2] O. Dos̆LÝ, P. ŘEHÁk, Half-linear Differential Equations, Math. Stud., vol 202, North-Holland, 2005.

[3] S. B. Eliason, A Lyapunov type inequality for certain nonlinear differential equation, J. London Math. Soc. 3 (1970), 461-466.

[4] G. Guseinov, B. Kaymakcalan, Lyapunov inequalities for discrete linear Hamiltonian system, Comput. Math. Appl. 45 (2003), 1399-1416.

[5] P. Hartmann, Ordinary Differential Equations, second ed., Birkhauser, Boston, 1982.

[6] H. Hochstadt, On an inequality of Lyapunov, Proc. Amer. Math. Soc. 22 (1969), 282-284.

[7] C. LeE, C. YeH, C. Hong, R. P. AgARwal, Lyapunov and Wirtinger inequalities, Appl. Math. Lett. 17 (2004), 847-853.

[8] W. Leighton, On Lyapunov's inequality, Proc. Amer. Math. Soc. 33 (1972), 627-628.

[9] Z. NeHARI, On an inequality of Lyapunov, In "Studies in Mathematical Analysis and Related Topics", pp. 256-261, Stanford Univ. Press, Stanford, CA, 1962.

[10] B. G. PACHPATTE, On Lyapunov-type inequalities for certain higher order differential equations, J. Math. Anal. Appl. 195 (1995), 527-536.

[11] A. TIRYAKI, M. UNAL AND D. ÇAKMAK, Lyapunov-type inequalities for nonlinear systems, J. Math. Anal. Appl. 332 (2007), 497-511.

[12] X. WANG, Lyapunov type inequalities for second order half-linear differential equations, submitted to J. Math. Anal. Appl.

[13] X. YAnG, On inequalities of Lyapunov type, Appl. Math. Computation 134 (2003), 293-300.

[14] X. YANG AND K. LO, Lyapunov-type inequality for a class of even-order differential equations, Appl. Math. Computation 245 (2010), 3884-3890.

[15] X. YANG, Y. KIM AND K. LO, Lyapunov-type inequality for a class of odd-order differential equations, J. Comput. Appl. Math. 234 (2010), 2962-2969. 